\title{
Inequality in access to technology for telepsychiatry
}

\section{Daniel D. Storch, MD}

Editor's note: Readers' Forum is a department for correspondence from readers that is not in response to articles published in CURRENT PSYCHIATRY. All submissions to Readers' Forum undergo peer review and are subject to editing for length and style. For more information,contactletters@currentpsychiatry.com.

\section{T} he COVID-19 pandemic has brought to the fore inequalities in health care. ${ }^{1}$ In a letter recently published in the American Journal of Psychiatry, Nadkarni et $\mathrm{al}^{2}$ addressed the reality that there is not equal access to quality care (in this case, telepsychiatry). They reported challenges in converting their psychiatry ambulatory care center to a virtual platform at Brigham and Women's Hospital, which is affiliated with Harvard Medical School.

Previously, I had reported in CURRENT Psychiatry that patients at our small community mental health clinic outside Baltimore have much less audiovisual capability (they were able to receive telepsychiatry services via phone only, and not via video conferencing on a computer, smartphone, or tablet). ${ }^{3}$ Of 100 consecutive patients, we used telepsychiatry for 82 (18 were seen in person, including 14 who were seen for administration of long-acting injectable medications). Of the 82 patients receiving telepsychiatry from our facility, only 9 had video conferencing sessions (10.9\%).

I repeated the survey approximately 3 months later. Preliminary data of these 125 total patients showed a slightly higher percentage $(12.6 \%)$ had video conferencing sessions.

\section{Factors associated with limited access to technology}

Similar to what was reported by Nadkarni et $\mathrm{al}_{,}{ }^{2}$ in our extremely vulnerable population, socioeconomic factors affect access. Our patients are low income, and often do not own computers or smart phones. Nearly all our patients receive medical assistance and/or Medicare. Our patients are more likely to be members of a racial minority group -4 times the national average. Our patients are older. ${ }^{4}$ Patient age varies from 16 to 83 years; the mean age is 54 , and the median age is 56. Educational level is low. Nearly all of our patients who participate in video conferencing sessions are female. Approximately 15 of our patients have comorbid intellectual and developmental disabilities diagnoses, and at least that many have subsyndromal symptoms. Constantino et $\mathrm{al}^{5}$ commented on the multiple negative consequences of the COVID-19 pandemic on individuals with intellectual and developmental disabilities, including "frank disparities in access" to technology as well as gaps left by relying exclusively on telehealth.

Among our patients, being low income, a member of a racial minority group, older, less educated, male, and developmentally and/or intellectually disabled are risk factors for less access to video conferencing. ${ }^{3}$ Nadkarni et $\mathrm{al}^{2}$ also noted less broadband access for rural residents and less access and lack of digital health literacy in patients with limited English proficiency.

As Nadkarni et $\mathrm{al}^{2}$ suggested, we did contact our legislators, and emergency rules are
Dr. Storch is Medical Director, Catonsville Clinic, Key Point Health Services, Catonsville, Maryland.

\section{Disclosure}

The author reports no financial relationships with any companies whose products are mentioned in this article, or with manufacturers of competing products.

doi: $10.12788 /$ cp.0136

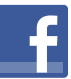

Discuss this article at www.facebook.com/ MDedgePsychiatry 


\section{Clinical Point}

\section{In our extremely vulnerable population, socioeconomic factors affect access to technology}

continuing. For now, we are managing fiscally. Although that certainly is important, it does not address the issue of inequality.

With this information, we are strongly encouraging our patients to participate in video conferencing sessions. We suspect that for some patients, the possibility of them participating in video conferencing sessions is greater than they have acknowledged. We are stepping up education and support, both informally through the patient's family and friends, and more formally through case managers who "lend" patients a device during home visits.

In summary, this inequality in access to the technology needed for telepsychiatry will loom even more prominently as we all move forward, both clinically and in policymaking.

\section{References}

1. Geller J. Structural racism in American psychiatry and APA: part 1. Psychiatric News. July 3, 2020. Accessed May 10, 2021. https://psychnews.psychiatryonline.org/doi/ full/10.1176/appi.pn.2020.7a18

2. Nadkarni A, Hasler V, AhnAllen CG, et al. Telehealth during COVID-19-does everyone have equal access? Am J Psychiatry. 2020;177(11):1093-1094.

3. Storch, DD. Treating patients during COVID-19: what I observed. Current Psychiatry. 2020;19(10):e5. doi:10.12788/cp.0054

4. Buis L, Singer D, Solway E, et al. Telehealth use among older adults before and during COVID-19. University of Michigan National Poll on Healthy Aging. Published August 2020. Accessed May 10, 2021. https://www.healthyagingpoll. org/report/telehealth-use-among-older-adults-andduring-covid-19

5. Constantino JN, Sahin M, Piven J, et al. The impact of COVID-19 on individuals with intellectual and developmental disabilities: clinical and scientific priorities. Am J Psychiatry. 2020;177(11):1091-1093. 